\title{
On the role of partially saturated soil strength in the stability analysis of a river embankment under steady-state and transient seepage conditions
}

\author{
Guido Gottardi ${ }^{1}$, Carmine Gerardo Gragnano ${ }^{1, a}$ \\ ${ }^{1}$ Department of Civil, Chemical, Environmental and Materials Engineering, DICAM, University of Bologna, Italy
}

\begin{abstract}
River flood risk is considered being one of the most costly hazards in Europe and under a further major potential impact of climate change, in combination with land-use changes and water management practices, flood risk is expected to increase for many river basins. In engineering practice, the design of river embankments is usually performed using simplified approaches, considering steady-state flow conditions induced by the retained water and almost neglecting issues related to partially saturated soils, thus leading to potentially heavily over conservative results of stability analyses. To provide a realistic assessment of river bank stability conditions and to get a more accurate prediction of flood risk it is necessary to consider river bank soil behaviour at different saturation degrees in connection with transient seepage flow. A numerical study on stability conditions of a specific river embankment focusing on the partially saturated soil strength contribution is presented herein. Seepage and stability analyses have been carried out using the information collected on river Secchia flooding case study, occurred north of the city of Modena (Italy) in January 2014. Limit equilibrium method has been adopted for assessing the overall stability in steady-state and transient flow conditions. Useful indications for accounting unsaturated soil strength in similar circumstances are finally provided in the paper.
\end{abstract}

\section{Introduction}

Riverbank stability analysis represents a key problem in engineering practice and a topical geotechnical research issue. Results of the studies related to this subject can provide useful suggestions both for risk assessment problems and for the definition of design approach criteria. However, these two aspects can substantially differ in relation to their main assumptions on which they are based. Typically, design approach analyses are conducted under steady state flow regime, assuming simplified initial conditions and mostly disregarding issues related to soil partial saturation, thus often leading to deliberately strongly over-conservative results in terms of actual probability of failure. On the other hand, risk susceptibility analysis should be founded on more realistic hypotheses, considering transient seepage through the embankment induced by time dependent boundary conditions, assuming pertinent initial conditions, and taking into account unsaturated and heterogeneous soils, thus influencing seepage characteristics and relevant strength parameters.,. A significant influence in riverbank stability can in fact be certainly ascribed to partially saturated soil strength, which in turn directly depends on soil hydraulic parameters and effective saturation degree, providing an additional, but variable, term able to substantially modify the bank probability of failure with time.
In order to assess the importance of taking into account soil river bank as partially saturated, a probabilistic study has been carried out using evidences, observations and data collected on a specific flooding case study, referring to bank's total sudden collapse occurred on January 19, 2014 on river Secchia, north of the town of Modena (Italy). In that case, decrease in soil suction values due to persistent high water levels along the river together with the widespread presence of animal burrows, clearly detected near the failed section and possibly existing in it before collapse, are supposed to have triggered an overall instability mechanism [1]; consequently, overtopping and erosion rapidly contributed to create a large breach in the river bank (Figure 1).

Aim of this study is to quantify the incidence of unsaturated soil strength on assessing the probability of bank instability under steady-state and transient seepage conditions and to stress its relevant influence on future risk assessment and design approach. Therefore, it is not meant to discuss further herein of the actual mechanisms that led Secchia's river bank to sudden total collapse and to the subsequent severe flooding of the surrounding countryside which caused one casualty, severe property losses and $€ 221$ million euros of total estimated damages.

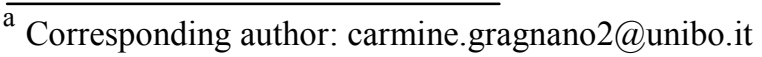




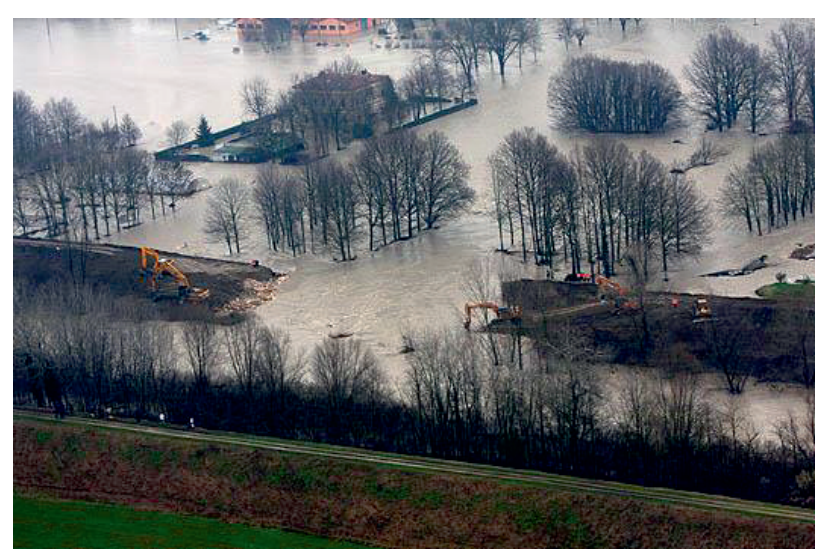

Figure 1. The breach area after 19/01/2014 flooding event.

\section{The case study}

The flooding area is located in the southern part of the Po valley (Italy), resting on a deep alluvial Pleistocene formation, locally at least $400 \mathrm{~m}$ thick. The morphology is resulted from the depositional and erosional activity of the Secchia and Panaro rivers, both Po's tributaries, which drain large areas of the Emilian Apennines. The geotechnical properties of the river bank's soil and subsoil were estimated by carrying out extensive site and laboratory investigations.

Site investigation involved the execution of cone penetration tests including pore-pressure measurements (CPTUs) running up to a 14-26 m depth, distributed on three different cross sections considered representative of the collapsed bank and located near the breach: section 1 was located on the right river side, $900 \mathrm{~m}$ upstream the breach area, section 2 was selected on the left river side, in front of the breach area and section 3 was taken again on the right river side, but immediately downstream the breach area. For each cross section, three CPTU tests were executed: on the river side, on the river bank top and on the landward side.

CPTUs performed on top were equipped with a seismic module for measuring the shear wave velocity propagation (SCPTUs). During their execution, pore pressure dissipation tests were also performed.

For the CPTUs result interpretation, semiempirical correlations proposed by Robertson [2] were used.

In particular, soil classification was derived by an iterative procedure, based on the value of the Soil Behavior Type Index
(Icn), estimated through the normalized cone resistance (Qt) and the normalized friction ratio (Fr).

Figure 2 plots the soil stratigraphic profile consistently defined by the results of in situ tests. Three different soil types were identified: firstly Unit R, composing the river bank soil, consisting of a complex alternation of silt with sand and sandy silt, with frequent thin sandy layers; the second, Unit B, composing the river bank foundation, consisting of $6.5 \mathrm{~m}$ average thickness sandy silt layers, locally clayey, primarily horizontally stratified; finally, Unit C, composing the subsoil, consisting of a primarily clayey layer with local sandy-silt sublayers, up to the maximum investigated depth.

Remoulded and undisturbed samples were taken from each section to determine relevant geotechnical properties by a comprehensive set of standard physical and mechanical tests. Fine grained soil percentage in Unit $\mathrm{R}$ turned out to be between 5 and $10 \%$, characterized by a PI $<10 \%$ and by a natural water content lower than the PL up to a 4-5 m depth from the river bank top. Soils sampled from Unit B are lithologically similar to the ones collected from Unit R; their fine grained fraction is again characterized by low plasticity, but with a natural water content typically greater than LL. The deeper clays, identified as the Unit C, are characterized by high PI values. Besides, local carbonate concretions were found at all depths, even in significant percentage. Unit $\mathrm{R}$ and Unit B soil strength parameters, distinctly for critical and peak conditions, were determined from in situ (CPTU and SCPTU) and laboratory tests (TxCID, TxCIU, DS). Unit $\mathrm{C}$ geotechnical parameters were estimated only by well-established correlations from CPTU and SCPTU results [3]. All estimated strength values are listed in Table 1.

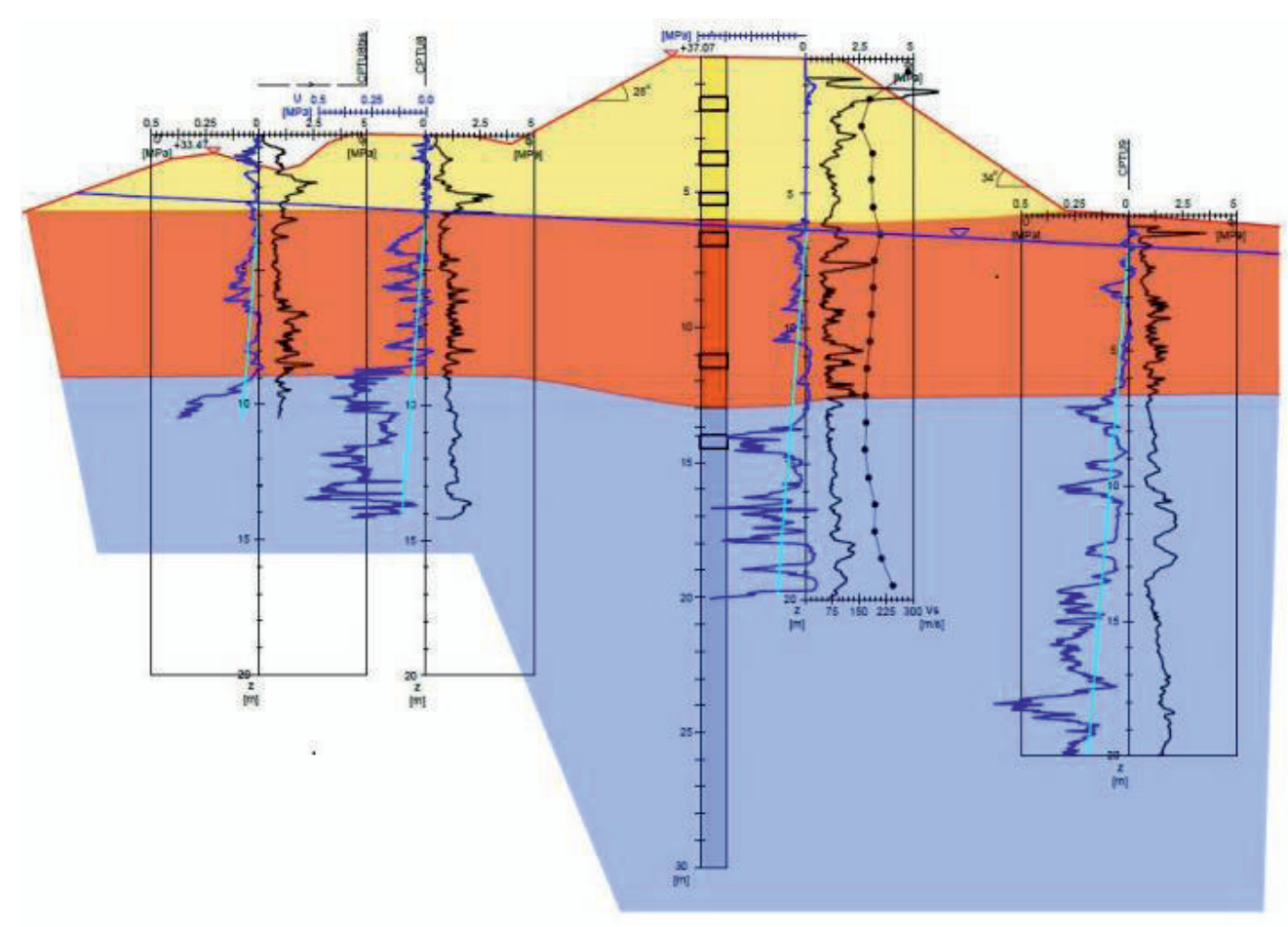

Figure 2. Stratigraphic profile and CPTUs results, Section 3. 
Table 1. Estimated strength soil properties.

\begin{tabular}{|c|c|c|c|}
\hline \multirow{2}{*}{ Soil Type } & \multicolumn{2}{|c|}{$\varphi^{\prime}\left(^{\circ}\right)$} & $c^{\prime}(\mathrm{kPa})$ \\
\cline { 2 - 4 } & $\begin{array}{c}\text { Mean } \\
\text { value }\end{array}$ & $\begin{array}{c}\text { Standard } \\
\text { deviation }\end{array}$ & $\begin{array}{c}\text { Estimated } \\
\text { value }\end{array}$ \\
\hline Unit R & 32.0 & 1.94 & 0.0 \\
\hline Unit B & 28.8 & 3.20 & 0.0 \\
\hline Unit C & 24.9 & 2.40 & 0.0 \\
\hline
\end{tabular}

Unit $\mathrm{R}$ soil retention and hydraulic properties have been carefully studied in laboratory through a series of nine evaporation tests conducted on undisturbed samples taken $600 \mathrm{~m}$ downstream the breach area at depths between 0.65 and $1.7 \mathrm{~m}$. The idea of using evaporation data to determine unsaturated soil hydraulic properties was introduced by Wind [4] and then slightly modified by several authors $[5,6]$. The evaporation tests of this study were performed according to the procedure proposed by Romano and Santini [7] for evaluating a parameter optimization method to determine the unsaturated hydraulic properties of different soil types. A widely used hydraulic model, the van Genuchten Mualem model [8] has been then adopted to fit the experimental data; this model comprises a non-hysteretic relationship (soil water retention curve) to estimate the effective degree of saturation, Se, from soil suction, $\mathrm{s}$ (difference between pore air pressure, $\mathrm{u}_{\mathrm{a}}$, and pore water pressure, $\left.\mathrm{u}_{\mathrm{w}}\right)$ :

$$
S_{e}(h)=\frac{\theta-\theta_{r}}{\theta_{s}-\theta_{r}}=\left[\frac{1}{1+\left(\alpha_{V G} \cdot s\right)^{n_{V G}}}\right]^{m_{V G}}
$$

$\theta, \theta_{\mathrm{s}} \theta_{\mathrm{r}}$ are the current, maximum and residual values of soil water content respectively, $\alpha_{\mathrm{VG}}$ and $\mathrm{n}_{\mathrm{VG}}$ are model parameters dictating the inflection point and the shape of the retention curve respectively. Notice that $n_{\mathrm{VG}}$ and $\mathrm{m}_{\mathrm{VG}}$ are dependent parameters, being:

$$
m_{v G}=1-\frac{1}{n_{v G}}
$$

The van Genuchten - Mualem model is employed to predict the variation of relative permeability $\mathrm{k}_{\mathrm{r}}$ with the effective degree of saturation, according to the following hydraulic conductivity function:

$$
k_{r}(h)=S_{e}^{0.5}\left[1-\left(1-S_{e}^{1 / m_{v G}}\right)^{m_{v G}}\right]^{2}
$$

The hydraulic permeability, $\mathrm{k}\left(\mathrm{S}_{\mathrm{e}}\right)$, is then expressed as the product of the saturated permeability, $\mathrm{k}_{0}$, estimated from in situ and laboratory test results, and relative permeability, $\mathrm{k}_{\mathrm{r}}$. By adopting such constitutive model and parameters, nine soil-water retention curves (SWRC) and hydraulic conductivity functions (HCF) were thus obtained.

For Unit B and Unit C, an estimation of hydraulic conductivity at saturation was made. Average values of all soil hydraulic properties mentioned above are listed in Table 2.
Table 2. Average values of estimated hydraulic soil properties.

\begin{tabular}{|c|c|c|c|c|c|}
\hline $\begin{array}{c}\text { Soil } \\
\text { type }\end{array}$ & $\begin{array}{c}\theta_{\mathrm{r}} \\
\left(\mathrm{m}^{3} / \mathrm{m}^{3}\right)\end{array}$ & $\begin{array}{c}\theta_{\mathrm{s}} \\
\left(\mathrm{m}^{3} / \mathrm{m}^{3}\right)\end{array}$ & $\begin{array}{c}\alpha_{\mathrm{VG}} \\
\left(\mathrm{kPa}^{-1}\right)\end{array}$ & $\begin{array}{c}\mathrm{n}_{\mathrm{VG}} \\
(-)\end{array}$ & $\begin{array}{c}\mathrm{k}_{0} \\
(\log (\mathrm{m} / \mathrm{s}))\end{array}$ \\
\hline Unit R & 0.079 & 0.395 & 0.164 & 1.328 & -5.804 \\
\hline Unit B & - & - & - & - & -5.725 \\
\hline Unit C & - & - & - & - & -8.886 \\
\hline
\end{tabular}

\section{Flow modelling and bank stability}

Seepage characteristics and stability conditions of the collapsed Secchia's river bank have been evaluated using a 2D numerical model based on actual geometrical, stratigraphical, geotechnical and hydrological data summarised in the previous section. Limit equilibrium analyses were performed both in steady-state and in transient flow conditions, as induced by river water levels and rainfall events registered since one month before the river bank failure and using the hydraulic parameters as deterministic variables, thus allowing only the soil shear strength parameter to account for the inherent soil variability.

\subsection{Saturated and unsaturated flow model}

Saturated and unsaturated flow was modelled using the software SEEP/W [9]. The code can perform a twodimensional, finite element seepage analysis using the equations of motion and mass conservation. Partial differential equations governing steady-state free surface flow in saturated soil conditions is given below:

$$
-k_{0} \nabla\left(\frac{w_{w}}{\gamma_{w}}+z\right)=0
$$

where $\mathrm{k}_{0}$ is the soil hydraulic permeability at saturation, $u_{w}$ is the pore water pressure and $z$ is the vertical elevation coordinate. In the case of unsaturated soils, the hydraulic conductivity is a function of water content and pore water pressure. Relationships between volumetric water content and pore water pressure and between hydraulic conductivity and pore water pressure are defined by soil-water retention curves (SWRC) and hydraulic conductivity functions (HCF), respectively. In transient seepage analysis, the water flow per unit area, $\mathbf{q}$, is calculated using generalized Darcy's law:

$$
-k_{r} k_{0} \nabla\left(\frac{u_{w}}{y_{w}}+z\right)=q
$$

Notice that only flow of water in the liquid phase has been considered in this work. Pore water pressure distributions were computed using adequate boundary conditions, described below, and assuming hydraulic parameters as deterministic variables, equal to their average values. Seepage analysis results, in terms of pore water pressure (PWP) distribution, are showed in Figure 3. In particular, are showed PWP distributions evaluated performing steady state and transient analysis using pertinent initial and boundary conditions, hereafter described; the PWP increment between two adjacent 
isolines is $10 \mathrm{kPa}$. Different suction distribution estimated in the riverbank soil significantly influence stability analyses.

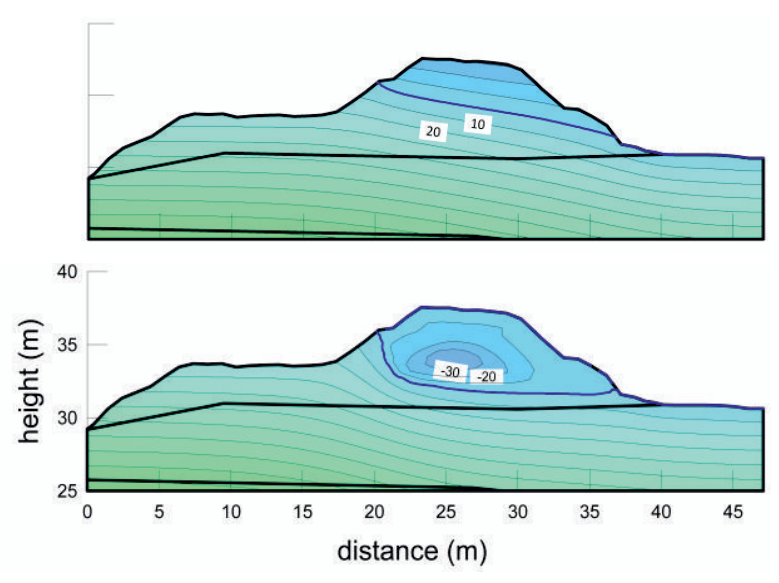

Figure 3. Results of steady state (top) and transient (bottom) seepage analysis in terms of PWP distribution.

\subsection{Initial and boundary conditions}

Numerical flow regime determination was conducted using specific initial and boundary conditions for steadystate and transient seepage analyses. Steady-state seepage analysis was conducted assuming a $35.9 \mathrm{~m}$ above msl retained water level on the river side, which is the maximum water level recorded during the specific flooding event (19 January 2014), water table at ground level on the landward side and soil permeabilities constant and equal to their saturated values. For a more accurate study of the embankment stability evaluation for that specific flooding event, flow characteristics have been also determined in transient conditions induced by the actual sequence of retained water levels and rainfall infiltrations, starting from realistic initial conditions. To this purpose, initial pore water pressure distribution was assigned starting from a water level at $30 \mathrm{~m}$ above msl, suction linearly decreasing to about $-40 \mathrm{kPa}$ in the middle of the bank, then increasing back up to zero value at the surface top level. The aim was to simulate a typical suction distribution in a wet period, characterized by rainfalls that tend to reduce the soil suction near the top surface by heavy water infiltration. This hypothesis has been considered admissible [10, 11, 12] also in absence of specific site measurements. It is worth noticing here how the actual initial distribution of pore water pressures is of vital importance, as it strongly affects the final results. Hydrostatic pore water pressure regime was considered beneath the water level. Retained water level and rain infiltration were then introduced as timedependent boundary conditions in the transient seepage analysis, assigning linearly variable total hydraulic head values on the river side nodes and unit rate of flow to boundary surfaces respectively. Input values have been analyzed using data recorded during river water level and rainfall events starting 25 December 2014 [1]. In Figure 4 recorded water levels and rainfalls are plotted together with the interpolating linear function used in the numerical model as total hydraulic head boundary condition.

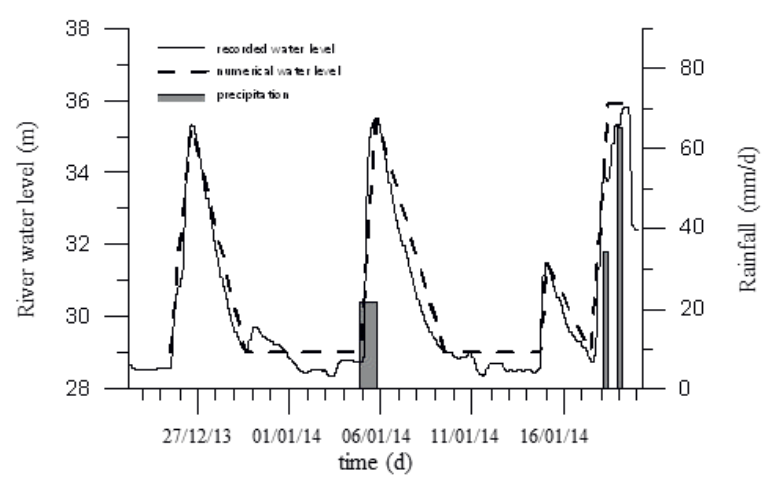

Figure 4. Flood hydrograph, rainfall hyetograph and numerical total hydraulic head boundary condition recorded and modelled from 25 December 2013 to 19 January 2014.

\subsection{Riverbank stability analysis}

Positive and negative pore water pressure distributions thus obtained were used as input data for the stability analyses performed by limit equilibrium with the Morgenstern-Price method [13], both under steady-state and transient flow conditions. Limit equilibrium analyses were performed for two critical surfaces, along landward and riverside slopes, identified in preliminary analyses and aimed at reproducing the possible onset of the actual river bank collapse (Figure 5).
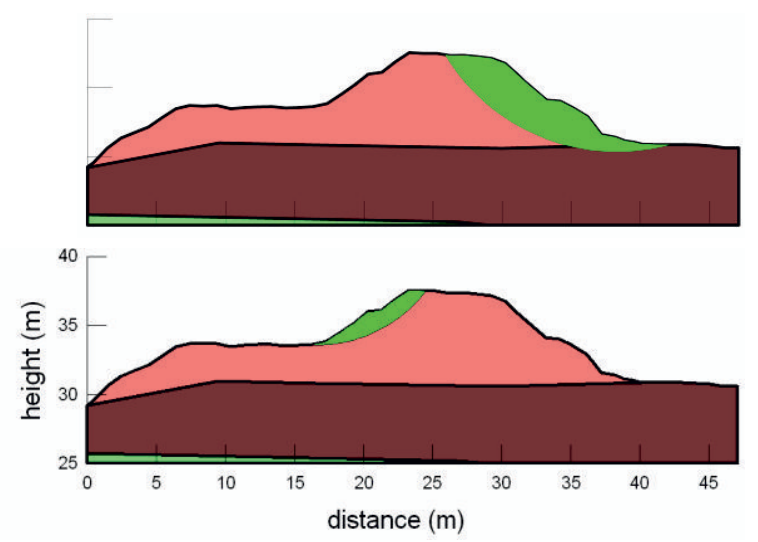

Figure 5. Landward (top) and riverside (bottom) critical surfaces identified for the stability analyses.

Vanapalli [14] failure criterion was used in limit equilibrium analysis for accounting unsaturated soil strength contribution, expressed in the form:

$$
\tau=c^{\prime}+\sigma_{\mathrm{n}} \tan \varphi^{\prime}+\left(u_{\mathrm{a}}-u_{\mathrm{w}}\right) S_{\mathrm{e}} \tan \varphi^{\prime}
$$

where $\tau=$ shear strength, $\sigma_{\mathrm{n}}=$ total normal stress, $\mathrm{u}_{\mathrm{a}}=$ pore air pressure, $u_{\mathrm{w}}=$ pore water pressure, $c^{\prime}=$ effective cohesion, $\varphi^{\prime}=$ friction angle in terms of effective stress, $\mathrm{S}_{\mathrm{e}}=$ effective degree of saturation. The shear strength contribution due to the matric suction $\left(\mathrm{u}_{\mathrm{a}}-\mathrm{u}_{\mathrm{w}}\right)$ is equal to $\tan \varphi$ ' up to the air-entry value (AEV) of the soil. In other words, the conventional equation for estimating the shear strength of saturated soils can be used up to the AEV for 
unsaturated soils. This equation suggests that there is a one to one relationship between the degree of saturation, $\mathrm{S}$, and the area of water contact along the shear plane in the soil. A previous formulation had been provided by Fredlund [15], expressed as:

$$
\tau=c^{\prime}+\sigma_{\mathrm{n}} \tan \varphi^{\prime}+\left(u_{\mathrm{a}}-u_{\mathrm{w}}\right) \tan \varphi^{b}
$$

where $\varphi^{\mathrm{b}}=$ angle expressing the rate of increase in strength relative to the matric suction $\left(u_{a}-u_{w}\right)$. As often observed $[16,17], \varphi^{\mathrm{b}}$ is a parameter strongly dependent on matric suction, varying up to a maximum value of $\varphi$ ' when the soil approaches saturation. Using a constant value of $\varphi^{\mathrm{b}}$ for accounting unsaturated soil strength contribution is certainly an approximation and could lead to errors in stability evaluation process when the matric range and the $\varphi^{\mathrm{b}}$ variability is not well defined. In this study, useful indication about $\varphi^{\mathrm{b}}$ value is provided for similar cases.

\section{Probabilistic stability analyses}

The probabilistic stability analysis of the river bank was performed with reference to both landward and river side slopes. Generally, in slope stability analyses only the soil shear strength parameters $\varphi$ ' and c' are considered to provide the probability of failure, assuming fully saturated conditions below the water table. However, in this work the role of partially saturated soil strength was also considered to assess the riverbank stability, in order to stress the importance of the soil hydraulic and retention parameters. Two cases were considered:

- Case 1, effective shear strength angle $\left(\varphi^{\prime}\right)$ as random variable and soil hydraulic permeabilities $\left(\mathrm{k}_{0}\right)$ constant and equal to saturated values, not taking into account unsaturated soil state;

- Case 2, effective shear strength angle $\left(\varphi^{\prime}\right)$ as random variable and soil hydraulic parameters $\left(\theta_{\mathrm{r}}, \theta_{\mathrm{sat}}, \alpha_{\mathrm{VG}}, \mathrm{n}_{\mathrm{VG}}\right.$, $\mathrm{k}_{0}$ ) as deterministic variables, equal to respective mean values (see Table 2).

The strength parameters of the soil beneath the embankment were assumed as deterministic values. Analyses of Case 1 have been performed only in steadystate conditions; for Case 2, steady-state (Case 2a) and transient (Case 2b) seepage analyses have been carried out, using the above described initial and boundary conditions to obtain the resulting pore water pressure distributions. A number of 100000 trials by Monte Carlo method were performed for estimating mean values and standard deviations of FS distribution together with the reliability index of each considered case and failure surface. The effective shear strength angle $\varphi^{\prime}$ of the soil bank was therefore the only random variable, with normal distribution defined by a mean value of $32^{\circ}$ and a standard deviation of $1.8^{\circ}$, with a covariance (CoV.) of around $6 \%$. Analysis results, summarized in Table 3, are presented in terms of mean values and standard deviations of Factor of Safety (FS), together with the reliability index and the probability of failure, for the landward and river side bank slope, respectively. In Case 1 , probabilistic stability analyses in steady state seepage conditions provide very low reliability index values (high probability of failure), highlighting a possibly serious critical condition for the riverbank. Instead, high reliability index values (probability of failure quite close to zero, but not null) are provided for the river side critical surface. Even if not representative for the specific flooding event, these results are, however, meaningful to stress the limited riverbank safety state in case of persistent high water levels in conjunction with harsh environmental conditions, as extreme rainfall, that could lead the bank soil close to saturation. In Case $2 \mathrm{a}$, stability analyses provide much lower values of probability of failure for both critical surfaces, reducing of at least one order of magnitude with respect to Case 1; mean values and standard deviations of factor of safety are increased, as well as its $\mathrm{CoV}$; this could be ascribed to the fact that in Case 2, $\varphi^{\prime}$ is twice used in the failure criterion, leading to a major dispersion of the results in terms of FS with respect to Case 1. Probabilistic stability analyses in transient seepage conditions (Case $2 b$ ) provide very high values of reliability index (very low probabilities of failure), for both landward and river side slope, not showing real chances of a riverbank instability. This result would suggest that the considered conditions are not able alone to account for the collapse occurred; in fact other issues, as hydraulic parameter variability and possible presence of animal burrows have been called upon to have triggered the instability mechanism leading to final collapse. Finally, a set of probabilistic analyses was carried out, for Case 2, both in steady-state and transient seepage conditions, in order to obtain the equivalent value of $\varphi^{\mathrm{b}}$ able to provide similar results in terms of mean FS; this was obtained using a deterministic value of $\varphi^{\mathrm{b}}$ equal to $23.5^{\circ}$. These analysis provided, thus, lower values for standard deviations and probabilities of failure, since $\varphi^{\prime}$ variability is not taken into account for unsaturated soil strength contribution. Equivalent values for $\varphi^{\mathrm{b}}$ are specific for a considered suction range and, therefore, could vary depending on the assumed critical surface.

Table 3. Results of MP limit equilibrium analyses using M-C method in steady state and transient seepage conditions.

\begin{tabular}{|c|c|c|c|}
\hline \multicolumn{2}{|c|}{ Case 1 } & Landward & Riverside \\
\hline Mean value & $\mu \mathrm{FS}$ & 1.031 & 1.418 \\
\hline $\begin{array}{c}\text { Standard } \\
\text { deviation }\end{array}$ & $\sigma \mathrm{FS}$ & 0.059 & 0.108 \\
\hline $\begin{array}{c}\text { Reliability } \\
\text { index }\end{array}$ & $\beta$ & 0.528 & 3.871 \\
\hline $\begin{array}{c}\text { Probability } \\
\text { of failure }\end{array}$ & $\mathrm{PF}(\%)$ & 30.441 & $8.10 \times 10^{-2}$ \\
\hline
\end{tabular}

\begin{tabular}{|c|c|c|c|}
\hline \multicolumn{2}{|c|}{ Case 2a } & Landward & Riverside \\
\hline Mean value & $\mu \mathrm{FS}$ & 1.145 & 1.735 \\
\hline $\begin{array}{c}\text { Standard } \\
\text { deviation }\end{array}$ & $\sigma \mathrm{FS}$ & 0.069 & 0.132 \\
\hline $\begin{array}{c}\text { Reliability } \\
\text { index }\end{array}$ & $\beta$ & 2.100 & 5.568 \\
\hline $\begin{array}{c}\text { Probability } \\
\text { of failure }\end{array}$ & $\mathrm{PF}(\%)$ & 1.302 & 0.000 \\
\hline
\end{tabular}




\begin{tabular}{|c|c|c|c|}
\hline \multicolumn{2}{|c|}{ Case 2b } & Landward & Riverside \\
\hline Mean value & $\mu \mathrm{FS}$ & 1.388 & 2.088 \\
\hline $\begin{array}{c}\text { Standard } \\
\text { deviation }\end{array}$ & $\sigma \mathrm{FS}$ & 0.084 & 0.159 \\
\hline $\begin{array}{c}\text { Reliability } \\
\text { index }\end{array}$ & $\beta$ & 4.588 & 6.837 \\
\hline $\begin{array}{c}\text { Probability } \\
\text { of failure }\end{array}$ & $\mathrm{PF}(\%)$ & 0.000 & 0.000 \\
\hline
\end{tabular}

\section{Conclusions}

In this paper, a probabilistic study of riverbank stability based on an accurate geotechnical and hydrological characterization, has been presented. Through the use of different flow model types and hypotheses on boundary and initial conditions, the importance of considering partially saturated soil strength contribution in assessing the probability of failure for riverbanks has been underlined. On the basis of results conducted with different failure criteria, an accurate estimate of an equivalent $\varphi_{\mathrm{b}}$ has been provided and could represent a useful indication for similar applications, in terms of specific soil types and matric suction ranges.

Accounting for unsaturated soil strength in steady-state conditions leads to less conservative and more realistic results, but it also requires to make use of many further information, as hydraulic properties of soil and initial and boundary conditions for a significantly long enough period. In addition, hydraulic parameters have been largely demonstrated to be strongly variables, even for mechanically and physically rather homogenous soils and therefore this issue should be also taken into account in order to achieve values of probability of failure consistent with the actual risk and, above all, to examine their evolution in conjunction with boundary condition evolution. Therefore hydraulic and retention parameters of riverbank soils, influencing seepage and strength characteristics, should be also treated as random variables; a specific uncertainty propagation analysis could thus lead to higher and more realistic values of probability of failure both under steady-state and transient seepage conditions.

\section{References}

1. L. D'Alpaos, A. Brath, V. Fioravante, G. Gottardi, P. Mignosa, and S. Orlandini, Available from http://Ambiente.Regione.EmiliaRomagna.it/geologia/notizie/notizie-2014/fiumeSecchia (2014)

2. P.K. Robertson. Can. Geotech. J., 46(11): 13371355. (2009)
3. P.W. Mayne, and R.G. Campanella. 16th International Conference on Soil Mechanics and Geotechnical Engineering, Osaka, Japan, 12-16 September, 2005. pp. 721-724. (2005)

4. G.P. Wind. Water in Unsaturated Zone, Wageningen, Netherlands, June 1966. pp. 181191. (1968)

5. S. Tamari, L. Bruckler, J. Halbertsma, J. Chadoeuf. Soil Science America J., 57(3): 642651. (1993)

6. O. Wendroth, W. Ehlers, J.W. Hopmans, H. Kage, J. Halbertsma, J.H.M. Wosten. Soil Science of America J., 57(6): 1436-1443. (1993)

7. N. Romano and A. Santini. Water resources research, 35(11): 3343-3359. (1999)

8. M. Th. van Genuchten. Soil Science of America J, 4(5): 892-898. (1980)

9. Geo-Slope International Ltd., Calgary, Canada. (2008)

10. N. Casagli, M. Rinaldi, A. Gargini, A. Curini. Earth Surf. Proc. and Landforms, 24: 253-277. (1999)

11. M. Rinaldi, N. Casagli, S. Dapporto, A. Gargini Earth Surf. Proc. and Landforms, 29:237-254. (2004)

12. G. Calabresi, F. Coleselli, D. Danese, G.P. Giani, C. Mancuso, L. Montrasio, A. Nocilla, L. Pagano, E. Reali, A. Sciotti. Canad. Geotech. J. 50(9): 947-960. (2013)

13. N. R. Morgenstern, and V.E. Price. Geotechnique, 15: 70-93. (1965)

14. S.K. Vanapalli, D.G. Fredlund, D.E. Pufahl and A.W. Clifton. Canad. Geotech. J., 33(3): 379392. (1996)

15. D.G. Fredlund, N.R. Morgenstern and R.A. Widger. Canad. Geotech. J., 15(3): 313 - 321. (1978)

16. D.G. Fredlund, H. Rahardjo. John Wiley \& Sons. (1993)

17. N. Lu and W.J. Likos. John Wiley \& Sons. (2004) 